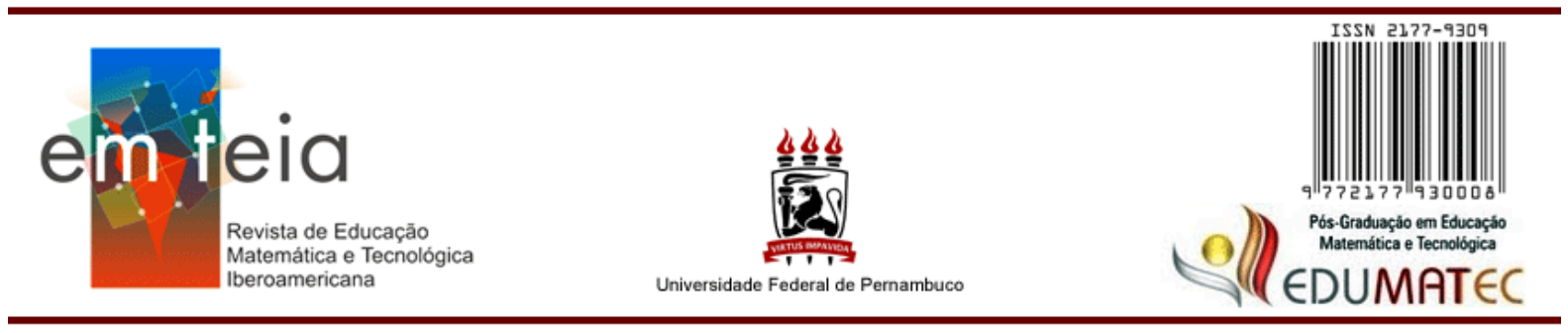

\title{
CONSTRUÇÃO DE NARRATIVAS DIGITAIS PARA A ALFABETIZAÇÃO: A PROFESSORA YOUTUBER
}

\author{
Joyce Cordeiro Heindyk Garcia ${ }^{1}$ \\ joycechgarcia@gmail.com \\ Núria Pons Vilardell Camas ${ }^{2}$ \\ nuriapons@gmail.com
}

\section{EXPLICAÇÃO NECESSÁRIA}

O presente trabalho é uma pesquisa empírica, da experiência inicial, que tenta analisar a percepção da possibilidade de usar narrativas digitais, feitas por meio de vídeos postados no Youtube, que abordem temáticas alfabetizadoras.

Tal ação nasce na observação inicial de crianças assistindo vídeos que são postados no Youtube e que geram o envolvimento, o interesse e a aprendizagem de diferentes atividades. Delas, temos desde o entretenimento ao assistir um desenho animado, ao aprender a fazer uma pipa ou, até mesmo, a composição da água, entre outras.

A observação inicial também nos demonstrou que muitas crianças possuem canais no Youtube, postando vídeos caseiros feitos com seus celulares, ou dos pais e amigos. Disto, surgiu-nos a questão inicial, enquanto pesquisadoras de educação e tecnologias: Como habitar as redes com autoria? Esta autoria poderia existir por meio de vídeos caseiros postados no Youtube com intenção pedagógica no processo de alfabetização?

A autoria ou coautoria nos levou a tentar entender, neste trabalho, como se dão as narrativas digitais, a partir da perspectiva de Bottentuit Junior, Lisbôa e Coutinho (2012, p. 193) e "conhecidas como narrativas interativas, narrativas midiáticas (ou multimídia),

\footnotetext{
${ }^{1}$ Mestra em Educação pela Universidade Federal do Paraná - UFPR. Pedagoga das redes Municipal de Curitiba e Estadual do Paraná, professora da Faculdade de Campina Grande do Sul - FACSUL.

2 Doutora em Educação pela Universidade Católica de São Paulo - PUCSP. Professora da Universidade Federal do Paraná - UFPR.
} 
storyttelling ou narrativas em ambiente digital", pois podem possibilitar "a implementação de estratégias de ensino e aprendizagem que colocam o aluno no centro do processo, permitindo que a utilização das TIC e da Internet se façam numa lógica de produção e não de mero consumo da informação disponível na rede global". Entretanto, não pudemos olvidar a necessidade de buscar entender: o que é uma narrativa? Que sujeitos sociais produzem narrativas?

Criou-se, assim, o canal "ALFABETIZAÇÃO para crianças" ${ }^{3}$. Os vídeos feitos e postados foram planejados, ao público infantil, de maneira lúdica e com intenção criativa daqueles que o assistirem. Fez parte do planejamento o fato de poder ser utilizado por professores, em sala de aula, pelas famílias em casa, de modo a poder colaborar com o aprendizado da escola e, até mesmo, como forma de lazer para as crianças usuárias. Os vídeos foram feitos para a faixa etária de 4 a 8 anos. Portanto, buscamos na ludicidade a potencialidade das narrativas que se possam construir a partir da narrativa inicial construída e postada no Youtube.

Definiu-se como objetivo: analisar os vídeos caseiros criados e postados no Youtube, no que tange a propiciar narrativas digitais que podem ajudar no processo de alfabetização de crianças.

Esta é uma pesquisa de abordagem qualitativa (FLICK, 2004; LÜDKE; ANDRÉ, 2015; CHIZZOTTI, 2010), que assume um caráter exploratório, porque constitui a primeira análise das atividades realizadas. Traz como resultados iniciais o relato de quatro professoras que utilizaram os vídeos em sala de aula, com alunos do 1ㅇano do Ensino Fundamental, em uma escola pública de Curitiba.

\section{NARRATIVAS DIGITAIS E POSSIBILIDADES EDUCATIVAS}

Numa escola que deveria estar em transformação e de acordo com seu tempo, temse, de um lado, a vontade transformadora e, de outro, certa impotência ante aquilo que se delega a outros, como o que denominamos formação continuada; falha e falta de políticas públicas que pensassem o futuro e investissem, pesadamente, no mínimo de infraestrutura que desse suporte à possibilidade de desenvolvimento educacional. Entenda-se, aqui, não apenas investir em equipamentos que são de extrema necessidade, mas também em conexão

\footnotetext{
${ }^{3}$ Disponível em: https://www.youtube.com/channel/UCFgqzbuhh6UGvR1ThPgUx10
} 
de alta qualidade, necessária em um mundo que já é digital, e em formações que propiciassem a autonomia intelectual de nossos professores, entre outros.

De algum modo, Bottentuit Junior, Lisbôa e Coutinho (2012, p. 192) nos lembram, em seus estudos, que "as mudanças precisam ocorrer, mais cedo ou mais tarde, sob risco da escola se afastar perigosamente da sociedade. Para que isso não aconteça, é preciso alcançar maiores níveis de qualificação e de conhecimentos, principalmente no domínio das tecnologias". Talvez, uma das colaborações aos autores aqui seja também superar sistemas decadentes e investir em novas práticas pedagógicas que deem conta desta velha modernidade.

Pensar em narrativas digitais é ter entendido os letramentos, entre eles o digital. Mas, sobretudo, é buscar entender o que é narrativa e se estamos a desconstruir ou não a perspectiva teórica da mesma para poder justificar seu uso. Portanto, partimos da definição mais ampla de narrativa que a entende

\begin{abstract}
como uma cadeia de signos com sentidos sociais, culturais e/ou históricos particulares, e não gerais. Esta definição significa que narrativas podem implicar conjuntos de signos que se movimentam temporalmente, causalmente ou de alguma outra forma socioculturalmente reconhecível e que, por operarem com a particularidade e não com a generalidade, não são reduzíveis a teorias. Nesta definição, a narrativa pode operar em várias mídias, inclusive em imagens imóveis. Ela deriva simplesmente da sucessão de signos, independentemente do sistema de símbolos, da mídia ou da "matriz semiótica" em que esta sucessão ocorre. No entanto, em uma narrativa, o movimento de signo para signo tem um significado social, cultural e histórico reconhecível. Uma série numérica é uma progressão de signos, mas seu sentido primordial é matemático e não se encontra em âmbitos sociais, culturais ou históricos. Um corolário desta definição é que as histórias não têm vigência universal; elas se valem de recursos simbólicos sociais, culturais e históricos particulares e operam dentro deles. A "leitura" de histórias pode, portanto, mudar ou se romper entre universos sociais, culturais e históricos distintos. Nessa definição, materiais visuais certamente podem constituir narrativas (SQUIRE, 2014, p. 273).
\end{abstract}

Portanto, partindo de Squire (2014), entendemos que as narrativas, mesmo que inseridas em teorias, como no nosso caso, a Alfabetização, representam a possibilidade de tecer aprofundamentos e reflexões necessárias no processo de aprendizagem.

\title{
TDIC E OS VÍDEOS NA ESCOLA
}

No Brasil, 58\% da população já têm acesso à internet (BRASIL, 2016), por outro lado, vemos que, mesmo com esse acesso, não se têm garantidos o conhecimento e a 
aprendizagem. Paulo Freire nos dizia que a escola deve estar à altura do seu tempo (PAPERT; FREIRE, 1995). Se uma criança que nasceu cercada de estímulos visuais chegar à escola, tenderá a buscar os mesmos estímulos que está acostumada no seu dia a dia. Se a instituição escolar não trabalhar com recursos que motivem o aluno a estudar, a atenção e o interesse serão mínimos, prejudicando a aprendizagem.

Por outro lado, as crianças que nasceram sem esses estímulos visuais proporcionados pela tecnologia também serão atraídas se a escola utilizar os recursos em sala de aula. Assim, o uso de vídeos pode ser uma ferramenta em sala de aula, auxiliando no processo de ensinoaprendizagem.

Entendemos como Tecnologia de Informação e Comunicação - TIC, com base nas leituras de Belloni (2001) e Coll e Monereo (2010), qualquer dispositivo que opera em sistema binário, eletrônico e integra a informação com a comunicação, através de um sistema de redes, por meio de acesso à internet. São tecnologias que servem para reunir, integrar e compartilhar informações.

Para Belloni (2001), as TIC são o resultado da fusão de três grandes vertentes técnicas: a informática, as telecomunicações e as mídias eletrônicas. Coll e Monereo (2010) completam a ideia dizendo que as TIC repousam sobre os mesmos princípios e criam "a possibilidade de utilizar sistemas de signos - linguagem oral, linguagem escrita, imagens estáticas, imagens em movimento, símbolos matemáticos (...) para representar uma determinada informação e transmiti-la" (COLL; MONEREO, 2010, p. 17).

A escola deve acompanhar o desenvolvimento da sociedade e se ressignificar em suas metodologias, em sua forma de conceber o conhecimento. $\mathrm{O}$ uso de aparelhos celulares como forma de acesso à internet corresponde a $89 \%$ dos entrevistados, já ultrapassando os computadores de mesa (40\%) e notebooks ou computadores portáteis (39\%) (BRASIL, 2016).

Assim, a escola deveria aproveitar pedagogicamente as TIC para atingir o objetivo de promover a aprendizagem. Quando falamos em utilizar as TIC na escola, precisamos ter em mente que o professor além de aprender a utilizar e estar de acordo com os objetivos de sua aula também precisa de tempo para incorporar essa tecnologia à sua aula.

Kenski (2013) observa que existe um tempo para que o professor utilize as tecnologias na escola. Esse tempo passa pela experiência do uso pessoal, para depois utilizar em suas práticas pedagógicas e se apropriar das tecnologias. Camas (2012), baseada nas experiências 
dos pesquisadores Dwyer, Sandholtz e Ringstaff (1997), diz que primeiro é preciso expor o professor às tecnologias de sua época, assim, ele passa a conhecer e ter a opção de adotar a tecnologia que lhe convém. A autora, em sua pesquisa, relata que, posterior à adoção, o professor se adapta às tecnologias, tornando melhor aquilo que já fazia sem elas. A próxima fase, segundo a pesquisadora, é o apropriar-se das tecnologias, com autonomia de uso, a ponto de apoderar-se delas com a finalidade de ensino-aprendizagem.

Entendemos, portanto, que, ao se apropriar da tecnologia, pode ocorrer o senso crítico de uso significativo, permitindo que o professor escolha a melhor ferramenta para o processo educacional, gerando o inovar, que é "a mudança na prática pedagógica" (CAMAS, 2012, p. 55). Talvez esse seja o maior desafio dos docentes na contemporaneidade: utilizar as TIC em metodologias de aprendizagem.

Faxina (2017) ressalta uma premissa difundida, de que uma imagem vale mais do que mil palavras. Para o autor, isso significa afirmar que se deve considerar a apresentação de vídeos como uma potente ferramenta, podendo ser, em muitos casos, mais eficaz do que a leitura de textos ou apresentações expositivas. Para o autor, o vídeo é "um instrumento de comunicação, uma ferramenta de informação, um recurso didático, formado por um discurso estabelecido a partir de uma sequência de imagens em movimento" (FAXINA, 2017, p. 4). Ainda de acordo com Faxina (2017), com o cinema, a televisão e o vídeo, retomamos o processo de empatia na compreensão da vida, das coisas, do mundo, por meio da imagem.

A teoria das inteligências múltiplas, proposta por Gardner (1994), considera importante o uso de recursos diversos para o desenvolvimento da aprendizagem. $\mathrm{O}$ trabalho com vídeos vem contemplar o campo da visão e audição, contribuindo para o desenvolvimento dessas inteligências.

\section{A ALFABETIZAÇÃO NA CONTEMPORANEIDADE}

Soares (2003) afirma que o acesso ao mundo da escrita é o processo de um indivíduo entrar nesse mundo. E isso se faz pela técnica e pelas práticas de uso dessa técnica. Para a autora, "ninguém aprende a ler e escrever se não aprender relações entre fonemas e grafemas - para codificar e para decodificar. Isso é uma parte específica do processo de aprender a ler e escrever [...]" (2003, p. 17). 
Para Morais (2012, p. 90), “[...] as oportunidades vividas, na escola e fora dela, são fundamentais para que os aprendizes desenvolvam determinadas habilidades fonológicas". Para o autor, é preciso que se tenha um bom trabalho escolar de promoção de certas habilidades fonológicas, desde o último ano da educação infantil, pois, o Sistema de Escrita Alfabética (SEA) se desenvolve pedagogicamente, se trabalhado em casa ou na escola.

[...] a apropriação do SEA não é uma questão maturacional, regulada por um relógio biológico, mas depende das oportunidades vividas dentro e fora da escola, entendemos que, para reduzir as desigualdades sociais (isto é, para enfrentar o apartheid educacional existente em nosso país), a escola pública precisa iniciar, no final da educação infantil, um ensino que permita às crianças não só conviver e desfrutar, diariamente, de práticas de leitura e produção de textos escritos, mas refletir sobre as palavras, brincando, curiosamente, com sua dimensão sonora e gráfica (MORAIS, 2012, p. 116).

Simões (2006) diz que o domínio das formas escritas se faz com a prática da língua, com muitas leituras e escritas. Contudo, "há estruturas básicas da fonologia da língua que podem e devem ser assentadas desde as primeiras séries do ensino fundamental, para que o estudante obtenha pontos de partida [...]" (SIMÕES, 2006, p. 15).

Para Simões (2006, p. 22), "A questão da nomenclatura quase sempre dificulta o aprendizado, uma vez que há uma tendência à memorização dos nomes sem, todavia, haver a assimilação do que significam".

Muitas crianças em idade escolar decoram o nome das letras mas não compreendem que essas letras produzem um som (fonemas). Assim, faz-se necessário um trabalho de consciência fonológica. Os vídeos do canal "Alfabetização para crianças" procuram trabalhar com o som das letras, despertando a consciência fonológica nas crianças.

A vogal é o som da voz, resultado da expiração pura, livre de obstáculos, pois provém de uma corrente de ar que vem dos pulmões e atinge a atmosfera livremente. Já o som consonantal, produzido pelas consoantes, é um som impuro, um ruído, que resulta de corrente de ar que atravessa o conduto respiratório enfrentando obstáculos antes de atingir a atmosfera (SIMÕES, 2006).

Por isso, a vogal tem um som independente, enquanto as consoantes precisam de apoio vocálico para produzir um som. É fundamental que a criança aprenda esse princípio, para entender o conceito de sílaba. Por sílaba, entende-se "o conjunto de fonemas emitidos a cada corrente de ar expirada" (SIMÕES, 2006, p. 27). 
Ferreiro e Teberosky (1986) afirmavam que a criança formula hipóteses a respeito do código, percorrendo um caminho que pode ser representado pelos níveis: pré-silábico, silábico, silábico-alfabético e alfabético. Mesmo antes da escolarização, a criança já vivencia o contato com o código e, à medida que vai sistematizando a aprendizagem, vai avançando nos níveis.

O Sistema de Avaliação da Educação Básica (SAEB), do ano de 2001, revelou as piores notas registradas: $33 \%$ dos alunos da quarta série ainda eram analfabetos. De 2003 em diante, os alunos começaram a apresentar melhorias (BRASIL, 2017).

Esse cenário mostra que ainda há muito para avançar na área de alfabetização. Para Soares (2003), é preciso orientar as crianças sistemática e progressivamente para que possam se apropriar do sistema de escrita. Isso é feito junto com o letramento, inserindo-as no contexto de textos reais, livros etc.

Alfabetizar é entendido como propiciar ao indivíduo a capacidade de ler e escrever. Conforme Camas (2012, p. 50), demonstra-se, citando Soares (1998, p. 31), que a alfabetização deve gerar o letramento. Neste sentido, concordamos com Kishimoto (2010, p. 19) que "o letramento envolve a identidade e agência do aprendiz na aquisição da linguagem", o que nos faz entender que a apropriação da escrita, como comenta Soares (1998, p. 30), “é diferente de ter aprendido a ler e escrever: aprender a ler e escrever significa adquirir uma tecnologia, a de codificar em língua escrita e a de decodificar a língua escrita; apropriar-se da escrita é tornar a escrita 'própria', ou seja, é assumi-la como sua 'propriedade' [...]".

É preciso superar o artificialismo dos textos das cartilhas e de práticas mecânicas e valorizar a função social da escrita. Mas não se pode esquecer que é preciso também trabalhar com conteúdos específicos da alfabetização, como discriminação entre letras e sons, análise e síntese de palavras e sílabas etc. É nesse trabalho conjunto de alfabetização e letramento, que a escola precisa caminhar.

Para Russo (2012, p. 25), “alguns professores hesitam ao dizer que adotam determinada cartilha, quando, na verdade o problema não está em qual cartilha seguir e, sim, em como usá-la". Para a autora, o perigo está em práticas sem significado e fora de contexto, que torna difícil a interiorização do conhecimento. Neste sentido, acreditamos que aliar a alfabetização ao letramento e às TDIC, neste estudo, o aliar os vídeos postados no Youtube ao processo de aprendizagem, poderá, talvez, ressignificar o processo de ensino e aprendizagem 
da criança, lógico que inserido em um contexto específico e metodologicamente utilizado em sala de aula. Um vídeo por si só não fará milagres.

\section{DESCRIÇÃO DA PESQUISA}

Na abordagem qualitativa, de acordo com Lüdke e André (2015, p. 12), “é cada vez mais evidente o interesse que os pesquisadores da área de educação vêm demonstrando pelo uso das metodologias qualitativas". Nesse sentido, concordamos com Chizzotti (2010, p. 84) que "os fenômenos são igualmente importantes e preciosos: a constância das manifestações e sua ocasionalidade, a frequência e a interrupção, a fala e o silêncio. É necessário encontrar o significado manifesto e o que permaneceu oculto".

Para Flick (2004, p. 22), os métodos qualitativos "consideram a comunicação do pesquisador com o campo e seus membros como parte explícita da produção de conhecimento, ao invés de excluí-la ao máximo como uma variável intermédia". Assim como o autor, entendemos que as subjetividades do pesquisador e dos que estão sendo estudados são parte do processo de pesquisa.

Os sujeitos desta pesquisa foram 4 professoras do Ensino Fundamental, do Município de Curitiba, que trabalharam com os vídeos em suas aulas. O instrumento utilizado para a coleta dos dados foi a carta narrativa (LIMA, 2006, p. 140), com o objetivo de os professores relatarem como eles observavam o uso dos vídeos do Youtube na sua prática pedagógica. Essa carta narrativa tem o objetivo de dar voz aos professores pesquisados.

Corroborando a escolha da carta narrativa (LIMA, 2006), Sousa e Cabral (2015, p. 156) dizem que

\footnotetext{
A carta narrativa, como opção metodológica de pesquisa e de formação de professores, insere-se na vertente investigação-formação, ao proporcionar aprendizagens, reflexão, revisitação ao passado, questionamentos sobre o presente numa visão prospectiva, permitindo a esses profissionais do ensino a revisão de posturas e crenças que foram se estabelecendo no decorrer da formação e da prática docente.
}

$\mathrm{Na}$ carta narrativa, conversou-se com as professoras, explicando a necessidade de se entender melhor o processo de uso de vídeos na alfabetização, e também a necessidade de terem a liberdade de dar a voz aos seus sentimentos e entendimentos acerca do projeto. Foi 
necessário ampará-las, com algumas perguntas, que não necessariamente precisariam ser respondidas na escrita manual delas.

\section{RELATO DO SUJEITO E A CRIAÇÃO DOS VÍDEOS}

No último semestre do mestrado, a pesquisadora pôde perceber que, para se apropriar totalmente das tecnologias, a ponto de inovar, precisaria não apenas utilizá-la, mas construir autorias com elas. Santos (2016), em uma entrevista para o programa "Salto para o Futuro da TV Escola", nos faz refletir que, para ter inclusão cibercultural, é preciso habitar as redes com autoria. Para ela, ainda falta clareza sobre os potenciais pedagógicos e comunicacionais das redes.

Estudando o contexto de tecnologia e vendo o interesse dos próprios filhos pelos vídeos do Youtube, contexto que propiciou a produção do canal, procurou-se ver se existiam outras produções de diferentes autorias que abordassem a alfabetização. Para isso, foi preciso assistir vários vídeos com a temática de alfabetização. Não foi encontrada nenhuma produção que trabalhasse o contexto de vídeos caseiros à alfabetização, ou explorasse os sons das letras.

Kenski (2013, p. 54) nos diz que "a mediação tecnológica facilita que novos projetos pedagógicos sejam criados, respeitando o ritmo de aprendizagem dos alunos de todas as idades e níveis de ensino [...]". Os vídeos no Youtube podem ser um exemplo de projeto que respeita o ritmo dos alunos, pois podem ser acessados e assistidos quantas vezes se fizerem necessárias, seja na escola ou em casa.

A primeira etapa da criação dos vídeos foi colocar no papel as ideias que estavam em mente. Essa é uma tarefa árdua, transformar os pensamentos em texto, escolhendo uma linguagem que fosse própria aos pequenos.

O primeiro vídeo a ser produzido foi a letra A. Foi preciso encontrar objetos que começassem com essa letra. Alguns itens a pesquisadora precisou comprar, especialmente, para a produção do vídeo, como o alface e o abacaxi. Os demais foram sendo separados à medida que surgiam as palavras, em mente, para exemplificar e concretizar o entendimento das crianças.

A gravação aconteceu utilizando um celular. Escolheu-se um ambiente da casa que contribuísse para esse momento. Para apoiar o celular e mantê-lo parado durante a gravação, 
improvisou-se, utilizando um suporte de partitura musical. Para iniciar a gravação, a pesquisadora viu que precisaria de alguém para arrumar o celular no ângulo correto e alguém que pudesse iniciar e parar as gravações. Foi então que entrou em cena a figura do filho mais velho. Com apenas dez anos, ele participou como "câmera man" de sua mãe em todas as edições do vídeo.

Na primeira gravação, os nomes dos objetos foram escritos em papel sulfite. Após a montagem do vídeo, verificou-se que a legibilidade das palavras escritas em papel não estava boa, o ideal seria editar o vídeo, colocando as palavras escritas do papel na própria tela da imagem.

Assim, caminhou-se para outro desafio, pois a pesquisadora nunca havia editado um vídeo, apenas tinha conhecimento em edição de áudios. Então, procurou-se um aplicativo para celular que atendesse à necessidade de edição do vídeo. Encontrou-se o VideoShow ${ }^{4}$, um aplicativo gratuito para celular, que permitiu fazer todas as edições.

Para Valente (2005), o domínio do técnico e do pedagógico devem acontecer juntos, simultaneamente. Ele defende que o educador "deve conhecer o que cada uma dessas facilidades tecnológicas tem a oferecer e como pode ser explorada em diferentes situações educacionais" (2005, p. 23).

Assim, aprendeu-se a explorar o aplicativo para uma necessidade educacional. Foi com a prática, na tentativa e erro, que se editaram os vídeos do canal. À medida que foram sendo produzidos novos vídeos, foi-se aprendendo mais sobre as edições, colocando, além de legendas, gifs animados.

Observando as reações do filho mais novo da pesquisadora, de 4 anos de idade, notouse que cenas com brinquedos e brincadeiras são atrativos para crianças nessa faixa etária. Procurou-se introduzir fundo de cena com brinquedos, trazer objetos do mundo infantil como o "Homem Aranha" para ilustrar a palavra aranha, na letra A (Figura 1), os fantoches (Figura 2) no vídeo das junções de vogais, dentre outros.

\footnotetext{
${ }^{4}$ Disponível em: https://play.google.com/store/apps/details?id=com.xvideostudio.videoeditor\&hl=pt
} 
Figura 1 - Vídeo produzido que contextualiza o Homem Aranha

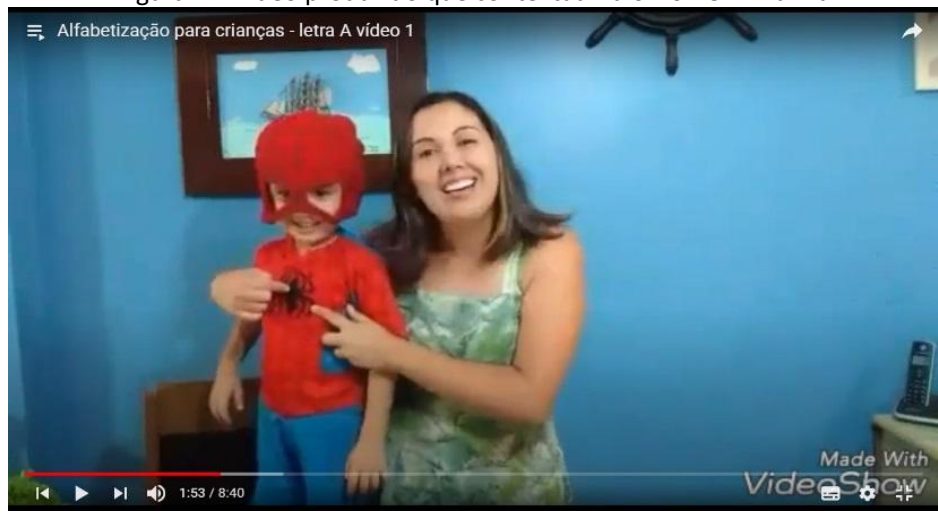

Fonte: Print do vídeo da letra A, no Youtube, feito pelas pesquisadoras (2017).

Na figura 1, temos um print do vídeo da letra A. Nesse vídeo, são explorados os sons que a letra faz e palavras que iniciam com o mesmo som. Para ilustrar as palavras, a pesquisadora mostra vários objetos com a letra A, como o avião, água, árvore, arroz, abajur, apontador etc.; entre esses objetos ela fala da aranha. Assim, para dinamizar o vídeo e atrair a atenção das crianças, ela chama o "Homem Aranha" para participar da cena.

Figura 2 - Vídeo produzido que contextualiza os fantoches

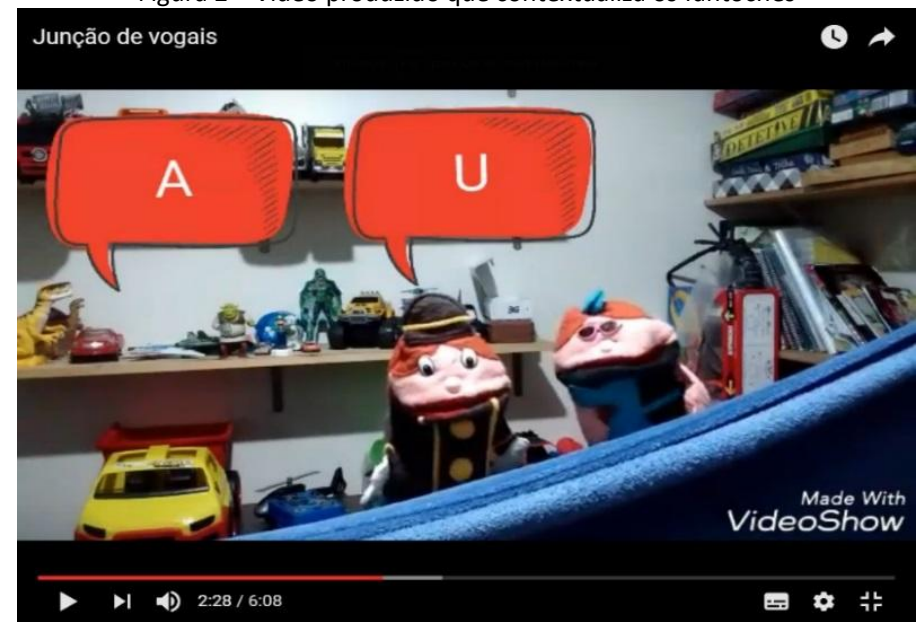

Fonte: Print do vídeo da junção de vogais, no Youtube, feito pelas pesquisadoras (2017)

No vídeo da Figura 2, a professora retoma o som das vogais e convida dois amigos para brincarem, o Tonico e a Lilica (fantoches). Nessa brincadeira, cada fantoche deveria falar o som de uma vogal e descobrir a palavra que formou. Em seguida, são contextualizadas as palavras, como no caso da palavra $\mathrm{AU}$, que mostra, posteriormente, cachorros latindo.

Os primeiros vídeos elaborados foram sobre as vogais. No final, criou-se um vídeo que trabalha a junção das vogais, buscando fazer com que as crianças percebessem que as palavras surgem das junções de letras. Posterior às vogais, iniciou-se a produção de vídeos trazendo as consoantes. 
Santos (2016) diz que o uso pedagógico da tecnologia deve estar junto com o uso cultural. Já faz parte da cultura dos alunos assistirem a vídeos pelo Youtube. Dessa forma, trazendo essa ferramenta para a sala de aula, o professor passa a introduzir e valorizar a cultura dos alunos.

Todos os vídeos produzidos no canal foram postados como Recursos Educacionais Abertos (REA), pela Biblioteca Federal do Paraná, e estão disponíveis para serem utilizados como aliados na alfabetização de crianças.

Decidiu-se postar os vídeos como Recursos Educacionais Abertos (REA) por serem entendidos como

\begin{abstract}
Materiais de ensino, aprendizado e pesquisa em qualquer suporte ou mídia, que estão sob domínio público, ou que estão licenciados de maneira aberta, permitindo que sejam utilizados ou adaptados por terceiros. $O$ uso de formatos técnicos abertos facilita o acesso e o reuso potencial dos recursos publicados digitalmente. Recursos Educacionais Abertos podem incluir cursos completos, partes de cursos, módulos, livros didáticos, artigos de pesquisa, vídeos, testes, software e qualquer outra ferramenta, material ou técnica que possa apoiar o acesso ao conhecimento (UNESCO/COL, 2011).
\end{abstract}

Neste sentido, acredita-se que, ao se publicar a experiência em REA, dá-se a oportunidade de outros professores poderem, além de aprender a usar a ferramenta, também ter o acesso e o reuso dos materiais, de forma a iniciarem uma maior compreensão das possibilidades e potencialidades das tecnologias no fazer pedagógico.

\title{
ANÁLISE DOS RESULTADOS
}

Por uma questão metodológica, a análise partiu do dizível de todas as palavras, tentando entender os sentidos e os significados das memórias das professoras, seguindo, assim, a Análise de Discurso (AD), sugerida por Orlandi (2007).

Entende-se que a AD permitiu, ao analisar as cartas narrativas, trazer o dito em relação ao não dito. Como diz Orlandi (2007, p. 59), "procurando ouvir, naquilo que o sujeito diz, aquilo que ele não diz mas que constitui igualmente os sentidos de suas palavras".

Para manter o sigilo da pesquisa, denominaremos cada professora por uma sigla P1 ao P4. Sobre a idade, formação e tempo de docência das professoras, podemos visualizar no quadro a seguir. 
QUADRO - DADOS DAS PROFESSORAS

\begin{tabular}{|c|c|c|c|}
\hline PROFESSORAS & IDADE & $\begin{array}{l}\text { TEMPO DE } \\
\text { DOCÊNCIA }\end{array}$ & FORMAÇÃO \\
\hline P1 & 38 anos & 15 anos & $\begin{array}{l}\text { Pedagogia. Especialização em Educação Especial e } \\
\text { Inclusiva. }\end{array}$ \\
\hline P2 & 46 anos & 23 anos & $\begin{array}{c}\text { Pedagogia. Especialização em Educação Inclusiva e } \\
\text { Especial. }\end{array}$ \\
\hline P3 & 36 anos & 15 anos & Letras. Mestrado em Educação. \\
\hline P4 & 42 anos & 16 anos & $\begin{array}{c}\text { Pedagogia. Especialização em Psicopedagogia e } \\
\text { Educação Especial. }\end{array}$ \\
\hline
\end{tabular}

FONTE: Dados coletados pelas pesquisadoras (2017).

Pode-se observar que as professoras se encontram na faixa etária dos trinta e seis a quarenta e seis anos. Todas possuem formação superior, com especialização e experiência na docência, pois todas possuem mais de dez anos de docência. Outro fator a destacar é que as quatro professoras possuem especialização em Educação Especial. A professora (P3) não colocou a especialização, mas, como trabalha com alunos de classe especial, também tem formação nessa área.

Nas questões de apoio à carta narrativa, foi sugerido que as professoras descrevessem o contexto que trabalharam com os vídeos. Temos as seguintes respostas:

Introduzindo as aulas de Língua Portuguesa (alfabetização) (P1).

Trabalho em Língua Portuguesa os vídeos, com músicas, histórias e letras; englobando os dois por exemplo (música da Dona aranha, letra A; O pato Pateta, letra P; histórias como A casa sonolenta, letra C; O gato de botas, letra G; A sopa supimpa, letra S... (P2).

Trabalho com alunos com deficiência intelectual. Meus alunos têm de 8 a 17 anos. $\mathrm{Na}$ sala trabalhamos as vogais e os seus sons em uma aula com atividades e figuras, em seguida passei o vídeo correspondente (P3).

Durante a apresentação das vogais, com o objetivo de ilustrar os sons relacionados às letras do alfabeto (P4).

Nos relatos, percebe-se que as professoras utilizaram os vídeos como complementação ou introdução para suas aulas, utilizando-se de outras formas, além dos vídeos, para sistematizarem a aprendizagem.

Sobre os objetivos em utilizar os vídeos em sala, as professoras dizem que

Demonstrar a função social da escrita de forma significativa e divertida (P1).

[...] Todas com a sequência didática, notei que com esta união as crianças estão atingindo os objetivos de aprendizagem, a maioria das turmas já estabelece relação 
entre fala e escrita, fazendo uso do valor sonoro convencional, produz escrita alfabética, mesmo não observando as convenções ortográficas da escrita (P2).

Meu objetivo foi apresentar as vogais de forma interativa e dinâmica. Todos eles gostam de estar conectados. O objetivo foi atingido (P3).

As crianças marcam o som com mais facilidade quando visualizam elementos que a situem com as letras (P4).

\section{Quanto à reação das crianças perante os vídeos, temos:}

Ficaram alegres; demonstrando bom humor e satisfação, relacionaram letras a personagens que gostava (P1).

Ao assistir os vídeos as crianças apresentam interesse pelo conteúdo, respondem as perguntas realizadas pelos apresentadores dos vídeos, quando aparece músicas com gesto imitam os gestos e a música que é cantada também, com personagens e crianças (dizem ser eles, o faz de conta), e ainda o tchau para pessoas, animais e personagens (P2).

Eles amaram. Não são crianças, mas devido à deficiência intelectual, possuem alguns gostos infantis. Durante cada vídeo, havia uma interação como se a apresentadora do vídeo estivesse presente. Repetiam, tentavam adivinhar, respondiam quando eram perguntados. Parecia um bate-papo. Falaram que a apresentadora era muito legal e queriam que ela fosse na escola para conhece-los. Não sabiam que eu a conhecia (P3).

As crianças interagem com os elementos e pessoas do vídeo, respondem, repetem os comandos (P4).

Quanto às contribuições dos vídeos para o processo de ensino-aprendizagem, as professoras responderam que

Sim, principalmente por perceberem que uma letra pode "produzir" diferentes sons (P1).

Os vídeos contribuíram sim no processo de ensino-aprendizagem dos alunos, o reforço das letras do alfabeto como também apresentação de novas figuras, objetos, nomes, pessoas para ampliar o vocabulário de nossos pequenos (P2).

Os vídeos contribuíram muito para o processo de ensino-aprendizagem, pois ilustra de forma satisfatória cada letra. É dinâmico, interessante e muda o ambiente causando uma movimentação alegre e divertida durante o ensino (P3).

Sim, reforça a memorização e relação grafema/fonema (P4).

Outra pergunta sugerida foi sobre o que as professoras mais gostaram nos vídeos; apareceram as seguintes respostas:

Nossos alunos são de uma geração na qual a tecnologia faz parte; sendo assim, percebi que aprendem e fixam melhor o conteúdo, aprendizado quando "ilustrado" por vídeos divertidos (P1). 
O que mais gostei na apresentação dos vídeos foi a forma, com a linguagem adequada para a faixa etária bem com os personagens utilizando criança o qual eles se identificam e ainda o trabalho com inúmeros objetos, focando o valor sonoro de cada letra inicial da palavra, o que facilita a aprendizagem da criança, sem confundir a cabecinha que ainda está no início do processo de alfabetização (P2).

Gostei da participação de outras crianças e objetos que elas gostam. Ficou mais real e familiar mostrando que aprender não precisa ser chato. Eu posso utilizar aquilo que eu gosto para desvendar a leitura e escrita (P3).

Diversificar os elementos (figuras, objetos) ampliando conhecimentos (P4).

Nota-se que os vídeos podem ser utilizados em sala de aula, como um recurso atrativo para os alunos, e que os mesmos contribuem no processo de ensino-aprendizagem.

\section{CONSIDERAÇÕES QUE NÃO SÃO FINAIS}

Retomando o problema de pesquisa: vídeos caseiros, postados no Youtube, podem auxiliar no processo de alfabetização de crianças? Pode-se dizer, com base nos relatos dos professores, que os vídeos auxiliaram as crianças no processo de alfabetização, promovendo aprendizagem. Os alunos que assistiram aos vídeos já identificam as vogais e sabem falar palavras que iniciam com o som das mesmas, conforme observado pela pesquisadora em visita à escola e pelos professores.

Quanto às questões auxiliares - como habitar as redes com autoria? Esta autoria poderia existir por meio de vídeos caseiros postados no Youtube com intenção pedagógica no processo de alfabetização? -, de acordo com os relatos, os professores estão trabalhando com vídeos em sala. As duas turmas da escola da pesquisadora já assistiram a todos os vídeos produzidos e aguardam a produção das demais letras. Entretanto, novas pesquisas deverão ser realizadas para desenvolver a autoria das crianças e professores, propiciando a aprendizagem, não somente do uso das TDIC, como também na criação de novas histórias. É possível o uso de vídeos "caseiros" com a intenção pedagógica.

Outro ponto de demasiada importância e que deverá ser mais explorado, em outras pesquisas, é a relevância de publicar como Recurso Educacional Aberto para o reuso de professores em sala de aula de materiais ou conteúdos didáticos. 
Esta pesquisa empírica inicial, do tipo relato de experiência, abre caminhos para um aprofundamento de novas pesquisas, que terão um campo fértil para analisarem os resultados e impactos dos vídeos em diversos e diferentes contextos.

\section{Referências}

BELLONI, Maria Luiza. O que é mídia-educação. Campinas, SP: Autores Associados, 2001.

BOTTENTUIT JUNIOR, João Batista; LISBÔA, Eliana S.; COUTINHO, Clara P. Revista Teias, Rio de Janeiro, v. 13, n. 27, p. 191-204, jan./abr. 2012 - Currículos: Problematização em práticas e políticas

BRASIL. Ministério da Educação. Portal do MEC. Alunos melhoram em matemática e língua portuguesa desde 2003. 2017. Disponível em:

<http://www.portal.mec.gov.br/component/tags/tag/31992>. Acesso em: 20 maio 2017.

BRASIL. Presidência da República. Secretaria de Comunicação Social. Pesquisa brasileira de mídia 2016: hábitos de consumo de mídia pela população brasileira. Brasília: Secom, 2016.

CAMAS, Nuria Pons Vilardell. A literacia da informação na formação de professores. In: TONUS, Mirna; CAMAS, Núria Pons Vilardell (Orgs.). Tecendo fios na educação: da informação nas redes à construção do conhecimento mediada pelo professor. Curitiba, PR: CRV, 2012. p. 47-68.

CHIZZOTTI, Antonio. Pesquisa em ciências humanas e sociais. 11. ed. São Paulo: Cortez, 2010.

COLL, César; MONEREO, Carles. Psicologia da educação virtual: aprender e ensinar com as tecnologias da informação e da comunicação. Porto Alegre: Artmed, 2010.

FAXINA, Elson (Org.). Importância sociocultural e aspectos políticos da televisão: disciplina do módulo I. Curitiba: UFPR, 2017.

FERREIRO, Emília; TEBEROSKY, Ana. Psicogênese da língua escrita. Porto Alegre: Artes Médicas, 1986.

FLICK, Uwe. Uma introdução à pesquisa qualitativa. 2. ed. Porto Alegre: Bookman, 2004.

GARDNER, Howard. Estruturas da mente: a teoria das inteligências múltiplas. Porto Alegre: Artes Médicas, 1994.

KENSKI, Vani Moreira. Tecnologias e tempo docente. Campinas, SP: Papirus, 2013. 
KISHIMOTO, Tizuko Morchida. Alfabetização e Letramento/literacia no contexto da educação infantil: desafios para o ensino, para a pesquisa e para a formação. Revista Múltiplas Leituras, São Paulo, v. 3, n. 1, p. 18-36, jan. jun. 2010.

LIMA, M. S. L. Docência e Pesquisa em Formação de Professores: caminhos que se cruzam nas cartas pedagógicas. In: PIMENTA, S. G.; GHEDIN, E.; FRANCO, M. A. S. (Orgs). Pesquisa em Educação: alternativas investigativas com objetos complexos. São Paulo: Loyola, 2006.

LÜDKE, Menga; ANDRÉ, Marli E. D. A. Pesquisa em Educação: abordagens qualitativas. 2. ed. Rio de Janeiro: E.P.U., 2015.

MORAIS, Artur Gomes de. Sistema de escrita alfabética. São Paulo: Melhoramentos, 2012.

ORLANDI, Eni Puccinelli. Análise de discurso: princípios \& procedimentos. Campinas, SP: Pontes, 2007.

PAPERT, Seymour; FREIRE, Paulo. O futuro da escola. Diálogo gravado e documentado entre Paulo Freire e Seymour Papert. São Paulo: TV PUC-SP, 1995.

RUSSO, Maria de Fátima. Alfabetização: um processo em construção. 6. ed. São Paulo: Saraiva, 2012.

SANTOS, Edmea. TV ESCOLA. Salto para o Futuro. Tema: Tecnologia na Educação. Programa de televisão. 2016. Disponível em: <http://tvescola.mec.gov.br/tve/video/salto-para-ofuturo-tecnologias-na-educacao $>$.

SIMÕES, Darcilia. Considerações sobre a fala e a escrita: fonologia em nova chave. São Paulo: Parábola, 2006.

SOARES, Magda. Letramento: um tema em três gêneros. Belo Horizonte: Autêntica, 1998.

A reinvenção da alfabetização. Presença Pedagógica, Belo Horizonte, v. 9, n. 52, p.15-21, jul./ago., 2003.

SOUSA, Maria Goreti da Silva e CABRAL, Carmen Lúcia de Oliveira. A narrativa como opção metodológica de pesquisa e formação de professores. Revista Horizontes. V.33, no 2, p. 149158, jul/dez 2015.

SQUIRE, C. O que é narrativa? Civitas, Porto Alegre, v. 14, n. 2, p. 272-284, maio-ago. 2014

UNESCO/COL. Guidelines for open educational resources (OER) in higher education.

Vancouver: COL, 2011. Disponível em: 
<http://www.col.org/PublicationDocuments/Guidelines_OER_HE.pdf>. Acesso em: 07 out. 2012.

VALENTE, José Armando. Pesquisa, comunicação e aprendizagem com o computador: o papel do computador no processo ensino-aprendizagem. In: ALMEIDA, Maria Elizabeth Bianconcini; MORAN, José Manuel (Org.). Interação das tecnologias na educação. Salto para o Futuro. Brasília: Ministério da Educação, SEED, 2005. 